\title{
Desain Lean Production Dengan Aspek Sustainability dan Logika Fuzzy pada Value Stream Analysis Tools
}

\author{
Famila Dwi Winati ${ }^{*}$, Adhe Rizky Anugerah ${ }^{1 \#}$, Dwi Adi Purnama ${ }^{1 \star}$
}

\begin{abstract}
This article measures and identifies waste and designs alternatives to reduce waste in one SME in Yogyakarta, thus increasing efficiency. The lean manufacturing approach uses Value Stream Mapping that applies sustainability concepts. The research methodology used in this research is case study strategy. Based on the analysis of Current State Mapping there are many activities that are not important and should be reduced. The sustainability aspect in Gendhis Bag covers the environmental aspect with a 10\% limit on skin waste and 15\% for PVC waste. Energy consumption for production is 750 watts and labor cost is $\mathrm{Rp} 32,800$ per unit. Safety operators have a very small accident rate, while the largest Physical Load Index score is in the cutting department. Future state VSM shows that NNVA and NVA time can be significantly reduced and lead time can be reduced, so production can increase 12 units per day.
\end{abstract}

Keywords. VALSAT, VSM, fuzzy, sustainability.

Abstrak. Artikel ini mengukur dan mengidentifikasi pemborosan yang terjadi dan merancang alternatif untuk mereduksi pemborosan pada satu UKM di Yogyakarta, sehingga dapat meningkat efisiens.i Pendekatan lean manufacturing menggunakan Value Stream Mapping yang menerapkan konsep sustainability. Metodologi riset yang digunakan dalam penelitian ini adalah strategi studi kasus. Berdasarkan analisis Current State Mapping terdapat banyak aktivitas yang tidak penting dan harus dikurangi. Aspek sustainability dalam Gendhis Bag meliputi aspek lingkingan dengan batasan $10 \%$ untuk limbah kulit dan $15 \%$ untuk limbah PVC. Konsumsi energi pada untuk produksi yaitu 750 watt dan biaya untuk pekerja yaitu Rp 32.800,- per unit. Operator safety memiliki angka kecelakaan yang sangat kecil, sedangkan skor Physical Load Index terbesar terdapat di departemen pemotongan. Future state VSM menunjukkan bahwa waktu NNVA dan NVA dapat berkurang secara signifikan serta lead time dapat dikurangi, sehingga produksi dapat meningkat 12 unit per hari.

Kata Kunci. VALSAT, VSM, fuzzy, sustainability.

\section{Pendahuluan}

Sektor industri di Indonesia mengalami perkembangan yang cukup pesat. Sektor industri merupakan salah satu sektor ekonomi yang sedang dikembangkan di Indonesia sebagai sektor penggerak kemajuan sektor ekonomi lainnya. Kekuatan struktur industri

\footnotetext{
1 Prodi Teknik Industri, Fakultas Teknologi Industri, Universitas Islam Indonesia, Jl. Kaliurang Km 14,5, Sleman, Yogyakarta, Indonesia 55584

* email: dwiwinatif@gmail.com

\# email: adherizky02@gmail.com

- email: dwiadi2.purnama@gmail.com

Diajukan: 02-04-2017

Disetujui: 16-06-2017
}

di Indonesia dapat dilihat dari kokohnya industri dasar, seperti IKM (Indutsri Kecil Menengah). Berdasarkan Jurnal Kajian Lemhannas RI edisi 14 (2012), jumlah IKM di Indonesia mencapai $90 \%$ dari total industri. Hal ini berarti, posisi IKM bagi perindustrian Indonesia sangatlah strategis. Berdasarkan data pada Badan Pusat Statistik, penyebaran unit IKM di daerah Jawa masih memimpin sebanyak 70\% atau 2.271.386 unit sedangkan 30\% lainnya tersebar di luar Jawa. Di daerah Yogyakarta sendiri, terdapat 57.665 unit IKM (BPS, 2015).

Pertumbuhan di sektor industri membuka peluang bagi IKM untuk mengembangkan usahanya. Kinerja perusahaan dapat dinilai dari kemampuan perusahaan untuk menciptakan proses yang efektif dan efisien, 
sehingga diperlukan adanya perbaikan secara terus-menerus (Pujotomo \& Raditya, 2011).

Gendhis Natural Bag merupakan salah satu perusahaan home industry yang terletak di Yogyakarta. Gendhis Natural Bag bergerak pada bidang kerajinan tangan (handmade), khususnya pembuatan tas-tas dari bahan natural dan sejenisnya. Pada setiap tahapan proses pembuatan tas di Gendhis Natural Bag terbilang konvesional. Dengan penggunaan teknologi yang sederhana ini, dimungkinkan terjadinya inefisiensi yang menimbulkan pemborosan baik dalam penggunaan bahan baku, proses produksi, maupun dalam penggunaan energi (Rinawati, dkk., 2013).

Peningkatan efisiensi merupakan kunci utama untuk menghadapi persaingan yang ketat dengan produk lain. Pemborosan (waste) seringkali terjadi pada perusahaan atau IKM tanpa disadari oleh pelakunya, sehingga tidak adanya pengukuran akan hal ini. Pemborosan sangat berpotensi untuk mengurangi efisiensi perusahaan (Pujotomo \& Raditya, 2011).

Oleh karena itu, diperlukan pengukuran pemborosan agar dapat digunakan untuk meminimalkan pemborosan tersebut. Salah satu caranya dengan pendekatan lean manufacturing (Fernando \& Noya, 2014), yang merupakan suatu konsep yang dapat meningkatkan kinerja lini produksi menjadi lebih baik, lebih cepat, dan lebih murah dengan ruang yang minim, inventori kecil, labor hour yang kecil, dan menghindari pemborosan (Womack, dkk., 1991). Dues, dkk. (2013) menyatakan bahwa penerapan lean manufacturing dapat memaksimalkan keuntungan dalam bidang lingkungan dan sosial dari proses manufaktur tersebut, dimana kedua faktor tersebut merupakan kajian sustainability.

Value Stream Mapping Tools (VALSAT) didefinisikan sebagai alat yang membantu untuk melihat dan memahami aliran bahan dan informasi dari keseluruhan proses bisnis yang melibatkan identifikasi tujuh waste (over production, inventory, over processing, unnecessary motion, waiting, defects, dan transportation) (De Steur, dkk., 2016). Dalam VALSAT ini, terdapat tujuh macam detailed mapping tools yang akan digunakan, dilakukan pembobotan dengan menggunakan skala ordinal low, mid, dan high dengan himpunan nilai $[1,3,9]$. Namun, pemberian bobot selama ini masih subjektif dan tidak pernah dijelaskan sebelumnya dan darimana nilai itu berasal (Saleh, dkk., 2012). Oleh karena itu, pada penelitian ini digunakan pendekatan fuzzy pada pemberian bobot detailed mapping tools dengan mengubah skala ordinal ke dalam skala triangular fuzzy, sehingga dapat mengurangi masalah ketidakpastian dan subjektifitas dalam pemberian bobot yang berdampak pada pengambilan keputusan.

\section{Metodologi}

Metodologi riset yang digunakan dalam penelitian ini adalah strategi studi kasus. Studi kasus membantu peneliti untuk mengkaji lebih dalam terkait objek atau subjek penelitian (Creswell, 2003). Tujuan utamanya adalah untuk membuktikan penerapan VSM dan sustainability untuk meningkatkan perfomansi sistem produksi di industri kreatif pembuatan tas. Penelitian ini melalui beberapa tahap.

Tahap 1 melakukan studi literatur mengenai penerapan value stream mapping dengan pendekatan fuzzy untuk pembobotan pada value stream analysis tool dan beberapa aspek sustainability, seperti : aspek lingkungan dan pekerja.

Tahap 2 melakukan identifikasi terhadap sistem produksi yang sedang berjalan di Gendhis Natural Bag dengan pengamatan langsung di lini produksi, yang mencangkup proses pemotongan, penjahitan, pengeleman, dan finishing.

Tahap 3 melakukan proses pengambilan data, yang dikelompokkan menjadi 3 kelompok, yaitu data untuk pembobotan jenis waste dengan mengggunakan metode fuzzyAHP dalam menentukan metode VALSAT 
yang tepat, current state pada VSM yang mencangkup aliran proses, waktu per proses, jumlah operator dan mesin yang digunakan, dan aspek sustainaibility.

Tahap 4 melakukan proses pengolahan data. Pembobotan jenis waste dilakukan dengan menggunakan logika fuzzy untuk mengurangi ketidakjelasan pemikiran expert dalam memberikan pembobotan (Beşikçi, 2016). Tahapan yang dilakukan pada fuzzy AHP sebagai berikut: konversi bilangan fuzzy menjadi triangular fuzzy number, fuzzy pairwaise comparison, hitung geometric mean, lakukan normalisasi, dan defuzifikasi.

Tahap 5 membangun current state map dari salah satu value stream anaysis tools terpilih. Current state adalah gambaran kondisi awal yang berisi aliran material dan informasi yang tersedia dalam value stream, seperti tugas, biaya, waktu untuk setiap proses, keterlambatan, dan lain sebagainya (Dotoli, dkk., 2011).

Tahap 6 melakukan analisis terhadap pemilihan value stream anaysis tools, current state mapping, dan aspek sustainability pada perusahaan Gendhis Bag dan akan diberikan rekomendasi perbaikan untuk meningkatkan performansi produksi yang saat ini berjalan di Gendhis Bag dengan analisis Kaizen yang kemudian dibangun future state map untuk memberikan usulan perbaikan.

\section{HASIL DAN PEMBAHASAN}

\section{Fuzzy-AHP}

Peneliti melakukan wawancara terhadap expert, yaitu manajer bagian produksi untuk memberikan bobot terhadap tujuh jenis waste. Hasil yang didapat kemudian diolah dengan pendekatan fuzzy-AHP dengan hasil seperti ditunjukkan pada Tabel 1.

Dari Tabel 1, kriteria defect merupakan kriteria dengan bobot tertinggi, mencapai 0,49. Manajemen ingin memastikan bahwa mereka hanya menghasilkan produk-produk yang berkualitas. Pihak manajemen perlu untuk mengelurkan biaya untuk rework apabila terjadi defect dan akan menganggu sistem produksi yang telah berjalan. Nilai bobot ini akan dikalikan dengan skor value stream analysis tools untuk memilih metode analisis yang paling sesuai.

\section{VALSAT}

VALSAT dapat membantu peneliti untuk menghilangkan waste yang ditemukan pada value stream. Bobot yang digunakan dalam penelitian ini merupan hasil modifikasi yang telah dilakukan oleh Saleh, dkk (2012) yang menggunakan pendekatan fuzzy untuk menentukan nilai low, medium, dan high. Nilai yang didapat dari fuzzy-AHP untuk pembobotan waste dikalikan dengan nilai bobot pada setiap tools pada VALSAT modifikasi dengan pendekatan fuzzy menghasilkan data seperti pada Tabel 2.

Tabel 1. Perbandingan pembobotan antara AHP dan Fuzzy AHP

\begin{tabular}{lcc}
\hline \multicolumn{1}{c}{ Kriteria } & $\begin{array}{c}\text { Bobot Perbandingan } \\
\text { Awal }\end{array}$ & $\begin{array}{c}\text { Bobot Perbandingan } \\
\text { Fuzzy }\end{array}$ \\
\hline Defect & 0.36 & 0,49 \\
Excessive Transportation & 0.17 & 0,17 \\
Inappropriate Process & 0,17 & 0,22 \\
Overproduction & 0.03 & 0,06 \\
Unnecessary Motion & 0.02 & 0,03 \\
Unnecessary Inventory & 0.09 & 0,13 \\
Waiting & 0,15 & 0,22 \\
\hline
\end{tabular}


Tabel 2. Pemilihan value stream analysis tools

\begin{tabular}{lcccccccc}
\hline \multicolumn{1}{c}{ Waste } & Bobot & PAM & SCRM & PVF & QFM & DAM & DPA & PS \\
\hline Overproduction & 0,06 & 2,40 & 4,00 & & 1,30 & 4,75 & 3,25 & \\
Waiting & 0,22 & 9,00 & 9,00 & 1,50 & & 4,75 & 3,25 & \\
Transport & 0,17 & 9,00 & & & & & & 1,25 \\
Inappropriate Processing & 0,22 & 9,00 & & 4,35 & 1,30 & & 1,35 & \\
Unnecessary Inventory & 0,13 & 3,32 & 9,00 & 4,35 & & 9,00 & 3,25 & 1,25 \\
Unnecessary Motion & 0,03 & 9,00 & 2,90 & & & & & \\
Defects & 0,49 & 2,40 & & & 9,20 & & & \\
\multicolumn{1}{c}{ Total Skor } & & 7,58 & 3,53 & 1,89 & 4,83 & 2,52 & 1,64 & 0,37 \\
\hline
\end{tabular}

Tabel 3. Data kegiatan VA, NNVA, dan NVA, lead time dan cycle time

\begin{tabular}{lccc}
\hline Activity & Jumlah & Time (Second) & Percentage \\
\hline VA & 89 & 3804 & $58.28 \%$ \\
NNVA & 38 & 377 & $5.78 \%$ \\
NVA & 78 & 2346 & $35.94 \%$ \\
Cycle Time & & & 3804 \\
Lead Time & & \multicolumn{3}{r}{6527} & \\
\hline
\end{tabular}

Dari Tabel 2, metode PAM merupakan metode yang akan digunakan untuk menganalisis waste yang ada di Gendhis Bag. Process activity mapping (PAM) merupakan tool untuk memetakan keseluruhan aktivitas secara detail guna mengeleminasi waste, ketidakonsistenan, dan keirasonalan di tempat kerja. Process activity mapping akan memberikan gambaran aliran fisik dan informasi, waktu yang diperlukan untuk setiap aktivitas, jarak yang ditempuh dan tingkat persediaan produk dalam setiap tahap produksi.

\section{Pengembangan Current State Mapping}

Pemetaan menggunakan VSM ini bertujuan untuk memberi gambaran umum yang berkaitan dengan waktu proses sehingga dapat diketahui value added dan non value added activity.

Current state adalah gambaran kondisi awal yang berisi aliran material dan informasi yang tersedia dalam value stream, seperti tugas, biaya, waktu proses, keterlambatan, dan lain sebagainya (Dotoli, dkk., 2011). Dari hasil pengamatan didapatkan bahwa untuk membuat sebuah tas rajut, produk akan melewati 14 rangkaian proses utama yang terdiri dari 205 aktivitas. Aktivitas ini kemudian akan diklasifikasikan menjadi lima kategori aktivitas, yaitu operasi, transportasi, inspeksi, storage, dan delay. Dengan data tersebut, dapat diidentifikasi operasi kritis, menghitung waktu VA dan NVA, total waktu proses, cycle time, lead time, dan rasio proses (Jasti \& Sharma, 2013). Aktivitas waktu untuk current state berdasarkan kondisi IKM Ghendis Natural Bag, terdiri dari operasi 115 aktivitas, transportasi 12 aktivitas, inspeksi 3 aktivitas, dan delay 75 aktivitas.

Berdasarkan pada data yang telah didapatkan, maka kegiatan-kegiatan VA, NNVA, dan VA dapat diidentifikasi. Data jumlah waktu dan aktivitas untuk kegiatan VA, NNVA, dan NVA serta lead time dan cycle time pada keseluruhan proses produksi untuk produk tas rajut, ditunjukkan pada Tabel 3.

Current state mapping menunjukkan terdapat banyak aktivitas yang tidak penting (NVA) dan harus dikurangi, mencapai 78 aktivitas dengan waktu hingga 2346 second. Non-value added activity banyak terjadi pada proses membuat mulutan dan pada proses body assembling. Non-value added activity ini didominasi oleh aktivitas-aktivitas menunggu serta beberapa aktivitas set up alat dan bahan, seperti waktu set up lem sebelum digunakan, waktu menunggu setelah aktivitas pengeleman, mengambil alat di luar area 
Tabel 4. Waktu aktivitas untuk Future State

\begin{tabular}{|c|c|c|c|c|c|}
\hline & & Activity & Present & Future & Saving \\
\hline \multirow{6}{*}{$\begin{array}{l}\text { Work: } \\
\text { Manufacturing of } \\
\text { Knitting Bag }\end{array}$} & 0 & Operation & 115 & 114 & 1 \\
\hline & $\Rightarrow$ & Transportation & 12 & 10 & 2 \\
\hline & $\square$ & Inspection & 3 & 2 & 1 \\
\hline & 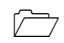 & Storage & 0 & 0 & 0 \\
\hline & \& & Delay & 75 & 14 & 61 \\
\hline & & Time & 6527 & 4377 & 2150 \\
\hline
\end{tabular}

Tabel 5. Time and activity classification process of Future State

\begin{tabular}{|c|c|c|c|c|c|c|c|}
\hline \multirow[b]{2}{*}{ No } & \multirow[b]{2}{*}{ Process } & \multirow[b]{2}{*}{ Time } & \multicolumn{5}{|c|}{ Activity } \\
\hline & & & $\bigcirc$ & $\Rightarrow$ & $\square$ & 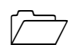 & $\mathscr{D}$ \\
\hline 1 & Making mulutan & 1485 & 19 & 3 & 0 & 0 & 3 \\
\hline 2 & Zipper assembling & 458 & 10 & 0 & 1 & 0 & 1 \\
\hline 3 & Sewing pocket & 408 & 4 & 1 & 0 & 0 & 2 \\
\hline 4 & Sewing labels & 52 & 2 & 0 & 0 & 0 & 1 \\
\hline 5 & Body and mulutan assembling & 249 & 12 & 0 & 0 & 0 & 2 \\
\hline 6 & Body assembling & 413 & 11 & 2 & 0 & 0 & 3 \\
\hline 7 & Making the cover of bag & 85 & 6 & 1 & 0 & 0 & 1 \\
\hline 8 & The bag's cover assembling & 194 & 10 & 0 & 0 & 0 & 0 \\
\hline 9 & Ring assembling & 324 & 11 & 2 & 0 & 0 & 0 \\
\hline 10 & Button assembling & 173 & 9 & 1 & 1 & 0 & 0 \\
\hline 11 & Making accessories & 66 & 2 & 0 & 0 & 0 & 0 \\
\hline 12 & Bag's locking assembling & 85 & 3 & 0 & 0 & 0 & 1 \\
\hline 13 & Tassel assembling & 238 & 10 & 0 & 0 & 0 & 0 \\
\hline 14 & Sum processing & 147 & 5 & 0 & 0 & 0 & 0 \\
\hline
\end{tabular}

stasiun kerja, adanya proses yang berulangulang pada tempat kerja yang berbeda dan berbagai aktivitas lainnya. Dengan adanya aktivitas menunggu dan pemborosan ini, dimana tidak ada penambahan nilai terhadap produk, maka diperlukan pengurangan atau mengalihkan sumber daya yang digunakan untuk mendukung aktivitas-aktivitas yang dapat menambah nilai, sehingga dapat menghemat biaya yang dikeluarkan (Rivera \& Chen, 2007).

\section{Future State Mapping}

Untuk mereduksi waste yang terjadi, penelitian ini menerapkan metode Kaizen yang berdasarkan pada adanya perbaikan kecil sebagai hasil dari upaya yang berkelanjutan yang melibatkan partisipasi setiap orang dalam organisasi dari manajemen puncak hingga karyawan pada tingkat yang lebih rendah (Maarof \&
Mahmud, 2016). Tiga pilar utama dalam penerapan Kaizen adalah house keeping, waste reduction, dan standardization (Imai, 1986). Adapun waktu proses berdasarkan usulan yang ditawarkan dapat dilihat pada Tabel 4 dan Tabel 5.

Langkah selanjutnya adalah merancang ulang gambaran keseluruhan dari sistem dengan mereduksi pemborosan dan menghilangkan beberapa non value added activities tersebut melalui future state value stream mapping (VSM). Future state VSM ini menggambarkan keadaan masa depan yang ideal dari sistem manufaktur yang telah dirancang untuk mewakili keadaan yang diinginkan dari kinerja visual (Dotoli, dkk., 2011).

Di Gendhis Natural Bag, non-value added activities didominasi oleh kegiatan-kegiatan set up, menunggu, mengambil bahan dan peralatan, serta proses merapikan stasiun 
Tabel 6. VA, NNVA, and NVA Activitas Future State, lead time, cycle time

\begin{tabular}{lccr}
\multicolumn{1}{c}{ Aktivitas } & Total & $\begin{array}{l}\text { Waktu } \\
\text { (Detik) }\end{array}$ & Percentage \\
\hline VA & 89 & 3804 & $86.91 \%$ \\
NNVA & 34 & 321 & $7.33 \%$ \\
NVA & 17 & 252 & $5.76 \%$ \\
Cycle Time & \multicolumn{3}{c}{3804} \\
Lead Time & \multicolumn{3}{c}{4377} \\
\hline
\end{tabular}

kerja, serta didominasi kegiatan manual yang dilakukan oleh manusia. Oleh karena itu perlu dilakukan analisis untuk mengurangi kegiatan-kegiatan yang tidak memberikan nilai tambah.

Penelitian ini memberikan usulan untuk mereduksi kegiatan yang tidak memberikan nilai tambah dengan menerapkan prinsipprinsip Kaizen. Penelitian juga mengusulkan redesign terhadap meja kerja yang memungkinkan untuk menyimpan segala jenis alat dan bahan yang digunakan untuk satu stasiun kerja berdasarkan pada prinsip Kaizen, sehingga dapat mereduksi waktu yang digunakan untuk mengambil bahan dan peralatan. Waktu menunggu pengeringan menjadi aktivitas yang dominan pada proses pembuatan produk tas rajut. Usulan yang diberikan adalah penambahan alat sederhana berupa solar dryer yang dapat membantu pengeringan lem lebih cepat. Sedangkan aktivitas-aktivitas setup dan persiapan peralatan merupakan aktivitas yang tidak perlu dilakukan dan dapat dihilangkan dengan melakukan pengaturan dan setup pada awal dan akhir jam kerja.

Future state VSM pada Tabel 6, menunjukkan bahwa waktu NNVA dan NVA dapat berkurang secara signifikan, serta lead time dapat dikurangi dari 6527 detik menjadi 4377 detik. Dengan menerapkan perubahan seperti yang diusulkan oleh peneliti, produksi dapat meningkat dari 28-30 unit menjadi 42 unit per hari.

\section{Aspek Sustainability}

The US Department of Commerce (US DOC, 2010) mendefinisikan produksi berkesinambungan sebagai penciptaan produk yang menggunakan proses dengan meminimalkan dampak lingkungan yang negatif, menghemat energi dan sumber daya alam, yang aman bagi karyawan, masyarakat, dan konsumen dan ekonomis.

Faktor lingkungan berkaitan dengan berapa banyak limbah yang dihasilkan selama proses produksi dari Gendhis Bag. Proses produksi tas pada Gendhis Bag terdiri dari tiga jenis bahan baku utama yaitu kain, PVC, dan kulit, dengan perencanaan awal produksi untuk kain memiliki batasan limbah maksimal sebanyak $10 \%$ dari total kain yang digunakan, PVC memiliki batasan limbah yang dihasilkan maksimal sebanyak 15\%, dan kulit memiliki limbah yang dihasilkan maksimal sebesar 10\%. Sehingga dengan batasan limbah yang dihasikan tersebut, produksi pada Gendhis Bag dapat mendukung terhadap kelestarian lingkungan yang berkelanjutan.

Pada tingkat proses untuk mencapai produksi berkesinambungan, perbaikan teknologi dan proses perencanaan merupakan pendorong utama dalam mengurangi konsumsi sumber daya, energi yang dikonsumsi, limbah dan dampak lingkungan. Gendhis Bag menggunakan konsumsi energi sebanyak 3000 watt yang digunakan untuk setiap 5 buah mesin produksi, dimana dalam sehari menggunakan mesin selama 7 jam kerja, sehingga dalam sehari Gendhis Bag menggunakan energi sebanyak 21000 watt atau $21 \mathrm{kWh}$. Penggunaan konsumsi energi Gendhis Bag dalam satu unit produksi yaitu sebanyak 750 watt.

Biaya yang dikelurkan oleh Gendhis Bag selama proses produksi terdiri dari biaya tenaga kerja dan biaya perawatan. Biaya 
tenaga kerja pada lini produksi yang terdiri dari 25 orang pekerja dengan biaya satuan Rp. 1.100.000,- setiap bulan, sedangkan produksi tas sebanyak 28 unit per hari. Biaya tenaga kerja untuk setiap unit produksi yaitu Rp 32.800,00. Sedangkan biaya perawatan yang dikeluarkan tidak dianggarkan, karena perawatan mesin dilakukan menggunakan 2 orang tenaga kerja yang ada di Gendhis Bag.

Proses produksi pada Gendhis Bag memiliki nilai kecelakaan setiap satuan unitnya sangat rendah bahkan sangat jarang terjadi. Kecelakan kerja yang terjadi dalam waktu 3 tahun terakhir hanya ada 1 kasus, yaitu pada proses produksi penjahitan karena adanya kecelakan pada pekerja yang tertusuk jarum jahit. Angka kecelakan untuk setiap unit produksi sangat kecil.

Physical Load Index (PLI), diperkenalkan oleh Hollman, dkk. sebagai ukuran sederhana yang cocok sebagai ukuran untuk penilaian pekerjaan fisik. Nilai PLI berkisar sebesar 0 - 56 dengan menilai menggunakan kuesioner yang memperhitungkan posisi tubuh dan penanganan berbagai beban.

Berdasarkan data Skor PLI yang diperoleh, dapat diketahui bahwa nilai PLI terbesar pada departemen pemotongan baik pekerja pemotongan 1 maupun pekerja pemotongan 2. Pekerja pemotongan 2 dengan jenis kelamin laki-laki memiliki nilai PLI terbesar yaitu 31,151. Departemen pemotongan memiliki nilai PLI terbesar, karena menggunakan beberapa posisi tubuh yang memiliki beban lebih besar dibandingkan dengan posisi tubuh pada departemen penjahitan dan departemen pengeleman. Pekerja pada departemen pemotongan sering melakukan gerakan membungkuk dan memutar pada badan, posisi lengan diatas bahu, posisi duduk dan berdiri, serta beban yang dibawa lebih besar dibandingkan dengan departemen lain.

\section{SIMPULAN}

Pengamatan pada current state mapping menunjukkan bahwa untuk membuat tas rajut, bahan akan melewati 14 proses primer yang terdiri dari 205 kegiatan. Pemetaan kondisi saat ini, banyak kegiatan yang tidak diperlukan (NVA) dan harus dikurangi, mencapai 78 kegiatan dengan sampai 2346 kedua. Non-value added didominasi oleh kegiatan menunggu dan beberapa alat mengatur dan kegiatan bahan. Future state mapping VSM menunjukkan bahwa waktu NNVA dan NVA dapat dikurangi secara signifikan serta lead time dapat dikurangi 6527 menjadi 4377 detik. Dengan menerapkan perubahan seperti yang diusulkan oleh para peneliti, produksi dapat ditingkatkan dari 28-30 unit menjadi 42 unit per hari.

\section{DAFTAR PUSTAKA}

BPS (Badan Pusat Statistik). (2015). Jumlah Perusahaan Industri Mikro dan Kecil Menurut Provinsi, 2013-2015. Tersedia secara Online pada laman https://www.bps.go.id/linkTableDinamis/view/id/1004 [diakses pada 18 Desember 2016].

Beşikçi, E.B. (2016). "An application of fuzzy-AHP to ship operational energy efficiency measures". Ocean Engineering, Vol. 121, pp.: 392 - 402.

Creswell, J.W. (2003). Research Design: Qualitative, Quantitative, and Mixed Methods Approach (Second Edition ed.). California: Saga Publication.

Commerce, T.U. (2010). The US Department of The International Trade Administration and The U.S. Department of Commerce's definition for Sustainable Manufacturing. The US Department of Commerce, 2010, "The International Trade Administration and The U.S. Departmen Available via http://www.trade.gov/competitiveness/sustainablemanuf acturing/how doc defines SM.as.

De Steur, H.; Wesana, J.; Dora, M.K.; Pearce, D.; Gellynck, X. (2016). “Applying value stream mapping to reduce food losses and wastes in supply chains: A systematic review”. Waste Management, Vol. 58, pp.:359 - 368.

Dotoli, M.; Fanti, M.; Rotunno, G.; Ukovich, W. (2011). “A lean manufacturing procedure using value stream mapping and the analytic hierarchy process". Proceedings of the IEEE International Conference on Systems, Man and Cybernetics, Anchorage, Alaska, USA, October 9-12, 2011.

El-Namrouty, K.A.; Abu Shabaan, M.S. (2013). "Seven waste elimination targeted by lean manufacturing case study: Gaza Strip Manufacturing Firms". International Journal of Economics, Finance, and Management Science, Vol. 1 (2), pp.: $68-80$.

Faulkner, W.; Templeton, W.; Gullett, D.; Badurdeen, F. (2012). "Visualizing Sustainability Performance of Manufacturing System Using Sustainable Value Stream (Sus-VSM)”. Proceedings of the 2012 International 
Conference on Industrial Engineering and Operations Management. Istanbul, Turkey, July 3-6, 2012.

Fernando, Y.C.; Noya, S. (2014). "Optimasi lini produksi dengan value stream mapping dan value stream analysis tools”. Jurnal Ilmiah Teknik Industri, Vol. 13 (2), pp. $125-133$.

Hollman, S.K. (1999). "Validation of a questionnaire of assessing physical work load”. Health. Vol. 25 (2), 105114.

Imai, M. (1986). Kaizen: The Key to Japan's Competitive Success. New York: McGraw-Hill.

Jasti, N.V.; Sharma, A. (2013). "Lean manufacturing implementation using value stream mapping as a tool: A case study from auto components industry”. International Journal of Lean Six Sigma, Vol. 5 (1), pp. $89-116$.

Pujotomo, D.; Raditya, A. (2011). “Penerapan lean manufacturing untuk mereduksi waste di industri skala UKM”. J@TI Undip: Jurnal Teknik Industri, Vol. 6 (3), pp.: $137-146$

Rivera, L.; Chen, F. (2007). "Measuring the impact of Lean tools on the cost-time investment of a product using cost-time profiles”. Robotics Computer Integration, Vol. 23 (6), pp.: $684-689$.

Rinawati, D.I.; $\quad$ Sari, D.P.; $\quad$ Nugroho, S.; Muljadi, F.; Lestari, S.P. (2013). "Pengelolaan produksi menggunakan pendekatan lean and green untuk menuju industri batik yang berkelanjutan (Studi kasus di UKM Batik Puspa Kencana)”. J@TI Undip: Jurnal Teknik Industri, Vol. 8 (1), pp. $43-50$.

Saleh, C.; Astuti, F.H.; Purnomo, M.R.A.; Deros, B.M. (2012). "Fuzzy identification of value stream analysis tools in lean manufacturing”. In Proceeding of 2012 International Conference on Uncertainty Reasoning and Knowledge Engineering, URKE 2012, pp.: $74-77$.

Womack, J.P.; Jones, D.T.; Roos, D. (1991). The Machine That Changed The World. New York: Harper Perennial. 